\title{
Spiritualitas Kesederhanaan (Simplicity) Sebagai Alternatif Bagi Gaya Hidup Materialis Kaum Muda
}

\author{
Himawan T. Pambudi ${ }^{1}$
}

$\mathbf{P}$ endahuluan

"Anak-anak Muda Makin Gila Belanja!"” Dalam berita tersebut, dilaporkan survei yang menunjukkan anak muda Indonesia makin giat belanja melalui situs jual beli online. Anak muda belanja melalui gadget serta membayar menggunakan kartu kredit, di mana gaya hidup konsumtif ini juga menjadi ciri khas anak muda di negara lainnya. ${ }^{3}$ Di Indonesia, anak muda memang menjadi target utama para pelaku usaha karena merupakan pangsa pasar yang amat besar. ${ }^{4}$ Semua itu dipadu dengan penghasilan anak muda yang makin membaik sehingga meningkatkan daya beli mereka. ${ }^{5}$ Fakta di atas perlu diwaspadai oleh gereja karena salah satu sumber dari meningkatnya stres dikalangan kaum muda adalah ketidakmampuan diri mereka untuk membeli serta mengikuti selera pasar. Terlebih, "belanja" bukan sekadar soal kebutuhan namun juga status sosial, afirmasi diri, gaya hidup, kebanggaan, dan berkoneksi dengan kompleksitas hidup urban perkotaan. Oleh karena itu, gereja dan pelayanan kaum muda perlu menawarkan gaya hidup alternatif yang menjawab kekosongan jiwa anak muda yang mencari keamanan (security) dan makna hidup dalam benda atau hal-hal materi.

Tulisan ini akan memaparkan gaya hidup materialis kaum muda, kemudian menawarkan spiritualitas kesederhanaan (simplicity) sebagai gaya hidup alternatif kaum muda masa kini.

\section{Gaya Hidup Materialis Kaum Muda}

\section{Definisi Gaya Hidup Materialis}

Kamus Oxford memberi arti kata materialism sebagai "a tendency to consider material possessions and physical comfort as more important than spiritual

1. Alum nus STT SAAT Malang dan sekarang melayani sebagai rohaniawan kaum muda di GKI Pregolan Bunder Surabaya.

2. SriNoviyanti, "Anak-Anak Muda Makin Gila Belanja," Anak-anak.Muda.Makin.Gila (diakses 30 0ktober 2015).

3. Adm in, "Tren Gaya Hidup Anak Muda," (diakses 1 Novem ber 2015).

4. Debnath Guharoy, "Analysis: How Powerful is the Young Indonesian Consumer?," (diakses 3 Novem ber 2015).

5. Fakta ini tercermin pada penghasilan mereka. Bila pada tahun 2011 hanya terdap at $28 \%$ anak muda dengan penghas ilan di atas Rp 3, 5 juta, maka tahun 2013 terjadi peningkatan 34, 2\% anak muda pada kelom pok tersebut, yaitu menjadi 57\% di tahun 2013. Lih.T.N, "Fakta Menarik tentang Anak Muda di Tanah Air," (diakses 1 November 2015). 
"Gaya hidup materialis," maka penulis memahaminya sebagai sikap mengagung-aoungkan kepemilikan benda, harta, uang, prestasi atau apapun yang ada di dunia ini lebih dari hal-hal rohani atau spiritual.

harian kaum muda. Pengaruh Budaya Pascamodern bagi Gaya
Hidup Materialis

Penulis mengambil perspektif Richard Dunn ${ }^{9}$ yang menjelaskan pengaruh budaya postmodern berdampak pada gaya hidup serta spiritualitas anak muda masa kini. Menurutnya, ada tiga cara pandang yang mempengaruhi anak muda. Pertama, anak muda berada da-
lam budaya yang memiliki cara pandang

values." ${ }^{\prime 6}$ Dalam tulisan ini, ketika berbicara mengenai "gaya hidup materialis," maka penulis memahaminya sebagai sikap mengagung-agungkan kepemilikan benda, harta, uang, prestasi atau apapun yang ada di dunia ini lebih dari hal-hal rohani atau spiritual. Gaya hidup ini membuat seseorang berpusat pada hal-hal material sebagai tujuan hidup sehingga mengambil perhatian, waktu, dan sumber daya. Gaya hidup materialis ini bisa juga disebut sebagai gaya hidup konsumerisme, yang memiliki paradigma bahwa mengkonsumsi sesuatu adalah baik, menyenangkan, serta suatu kebutuhan yang perlu dilakukan secara terus-menerus. ${ }^{7}$ Penulis akan memaparkan mengenai pengaruh budaya pascamodern bagi gaya hidup ini, ${ }^{8}$ setelah itu akan menguraikan tentang dampaknya bagi pemikiran kesedunia secara indriawi semata. Dunn menjelaskan ada tiga tahap dalam proses perubahan budaya:

(1) Tahapan ideasional, sebagai tahapan budaya dengan mentalitas yang melihat kebenaran dan nilai rohani sebagai satusatunya kebenaran dan nilai yang tertinggi. Tuhan dan dunia di atas merupakan realitas tertinggi dan paling benar, semua yang baik adalah apa yang Allah kehendaki.

(2) Tahapan idealistis. Seperti tahapan ideasional, tahapan ini menempatkan kebenaran dan nilai di atas yang lain. Namun tahapan idealistis juga menghargai realitas dan nilai dari dunia indriawi dan tidak memperlakukannya sebagai sesuatu yang tidak bermakna atau sama sekali tidak

6. http://www.oxforddictionaries.com/definition/english/materialism(diakses 3 November 2015); bdk. Kamus Besar Bahasa Indonesia yang juga memberi pengertian tentang materialis dengan pemahaman yang kurang lebih sama yaitu, materialis/ma·te-ri·alis/ /matérialis/ n 1 pengikut paham (ajaran) materialisme; 2 orang yang mementingkan kebendaan (harta, uang, dan sebagainya). Lih. (diakses 13 November 2015).

7. Dengan pengertian ini, ketika menggunakan istilah materialis penulis tidak merujuk pada paham filsafat materialisme ilmiah dalam kajian filsafat Barat, tentang perbedaan ini, lih. Steve Wilkins dan Mark L. Sanford, Hidden Worldviews: Eight Cultural Stories that Shapes Our Lives (Downers Grove: IVP Press, 2009), 45). Selain itu, meskipun sinonim, penulis tidak memakai istilah konsumerisme karena lingkupnya lebih sempit kepada berbelanja atau mengkonsumsi barang, sedangkan dengan memakai istilah gaya hidup materialis penulis merujuk pada banyak aspek seperti pemakaian waktu, kebiasaan liburan yang berlebihan, juga pencapaian status dan prestasi.

8. Penulis tidak mengatakan bahwa gaya hidup materialis ini baru muncul pada era postmodern. Maksud penulis adalah bahwa pengaruh postmodern membuat gaya hidup materialis semakin menjadi-jadi. Tentang filsafat postmodernism pembaca bisa melihat buku-buku pengantar filsafat.

9. Richard R. Dunn, Membentuk Kerohanian Anak Muda di Zaman Postmodern (Surabaya, Literatur Perkantas Jatim, 2012).

\section{0}

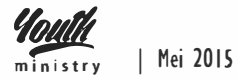


ada. Tahapan idealistis menekankan transendensi tetapi juga merangkul pentingnya dunia materi yang bisa diakses indra.

(3) Tahapan indriawi, di mana mentalitas indriawi adalah kebalikan dari mentalitas ideasional, mentalitas ini hanya tertarik pada semua hal yang bersifat materi dan bisa diakses oleh indra. ${ }^{10}$

Saat ini, kaum muda berada dalam budaya yang tampak jelas sudah dalam tahapan indriawi. Bukti mentalitas indriawi di sarana-sarana budaya pop anak muda yang tampil dalam media, internet dan acara sangat mudah ditemukan. Anak muda begitu membutuhkan sensasi yang didapatkan dari pengalaman-pengalaman indriawi tersebut, maka wajar mereka merasa bahwa apa yang mereka alami adalah realitas sebenarnya yang harus mereka miliki.

Kedua, anak muda berada dalam budaya yang menjunjung kesenangan pragmatis yang berujung pada kenikmatan sebagai allah mereka. Dunn mengungkapkan bahwa dalam suatu budaya indriawi, kebutuhan anak muda dipenuhi dengan mengkonsumsi pengalamanpengalaman menyenangkan atau produkproduk yang menjanjikan hasil menyenangkan. Daya tariknya ada pada kenikmatan ketika mengkonsumsi produk tersebut. Cara pandang ini menghasilkan pengejaran kesenangan yang "gila-gilaan" sebagai tujuan utama dari hidup. Anak muda akan berkata "jika enak, lakukanlah." Pada akhirnya mereka akan mengalami perubahan dan batasan moralitas. Apa yang dahulu menjadi tabu dan terlarang, sekarang menjadi wajar dan biasa karena hal tersebut menjadi pemenuh bagi kesenangan pribadi. Ketika sesuatu menjadi yang menyenangkan maka kesenangan pribadi menjadi ukuran dalam proses pengambilan keputusan dan moralitas. Tren anak muda yang mulai melihat moralitas yang disodorkan gerejawi adalah moralitas yang usang membuktikan perspektif ini mengejawantah dalam kehidupan anak muda. ${ }^{11}$

Ketiga, anak muda berada dalam budaya yang melihat pada keterikatan palsu mendatangkan makna bagi hidup mereka. Setelah budaya indriawi yang mengkonsumsi kenikmatan sebagai kesenangan, maka manusia mulai gagal menemukan makna di dalam identitas diri mereka. Anak muda tidak melihat makna hidup mereka terkandung dalam kebenaran mereka adalah ciptaan Allah. Individuindividu dalam generasi ini melihat pada "keterikatan palsu" untuk mendatangkan makna bagi hidup mereka. Keterikatan palsu muncul ketika "sesuatu di luar sana" memuaskan rasa memiliki dan makna hidup saya. Keterikatan palsu dapat muncul dalam beragam bentuk: internet, drugs, pacar, pekerjaan, artinya apapun itu yang memiliki dorongan untuk mendefinisikan identitas dan nilai pribadi

10. Richard R. Dunn, Membentuk Kerohanian Anak Muda di Zaman Postmodern, 49-50. Penulis berasumsi ada kaitan dengan perubahan worldview dalam filsafat Barat mengenai dunia supranatural dan natural, juga bangkitnya rasionalisme pencerahan dengan tahapan dalam budaya yang ada.

11. Perubahan perspektif moralitas dalam kehidupan anak muda dapat kita lihat bagaimana berubahnya mereka dalam melihat seks, keluarga, isu-isu homoseksual, politik dan ekonomi. (lih. Walt Mueller, Youth Culture 101 (Grand Rapids: Youth Specialties, 2007) 39-53; bahkan perspektif anak muda terhadap gereja semakin buruk, lih. David Kinnaman dan Gabe Lyons, UnChristian: What a New Generation Really Thinks about Christianity and Why It Matters (Grand Rapids: Baker Books, 2007), 26-30; David Kinnaman, You Lost Me: Mengapa Orang Kristen Muda Meninggalkan Gereja dan Memikirkan Ulang tentang Iman Mereka (Bandung: VisiPress, 2011), 160-163. 
mereka. Singkatnya, keterikatan palsu adalah apa yang diluar menentukan siapa saya. Pada akhirnya keterikatan yang palsu ini menghancurkan generasi muda dalam kesepian personal. ${ }^{12}$

Ketiga perspektif budaya postmodern tersebut akhirnya mengejawantah dalam gaya hidup materialis kaum muda. Jika di bagian ini penulis memperlihatkan pengaruh budaya yang mendasarinya, berikut ini penulis menguraikan pandangan dan praktik gaya hidup materialis yang ditampilkan kaum muda. Gaya Hidup Materialis dalam Keseharian Kaum Muda

Walt Mueller, mengungkapkan lima perspektif kaum muda mengenai "benda" atau "harta" yang menunjukkan gaya hidup materialis dalam keseharian anak muda. ${ }^{13}$

Pertama, "benda" memberikan mereka kebahagiaan. Kaum muda percaya bahwa harga diri dan kepercayaan dalam hidup mereka adalah berakar dengan apa yang mereka miliki, bagaimana mereka terlihat, apa yang mereka pakai, ke mana mereka pergi, alat transportasi apa yang mereka pakai, dan segala tetek bengek "tampilan luar." Kaum muda percaya bahwa I am what I have. Jadi, mereka merasa baik dengan diri mereka berdasarkan tampilan luar mereka, bukan tentang bagaimana Tuhan menciptakan mereka dengan unik sebagai gambar Allah. Sebuah penelitian mengatakan bahwa dua per tiga dari orangtua berkata bahwa anak mereka mendefinisikan harga diri atau kebahagiaan mereka dengan apa
Kaum muda percaya bahwa I am what I have. Jadi, mereka merasa baik dengan diri mereka berdasarkan tampilan luar mereka, bukan tentang bagaimana Tuhan menciptakan mereka dengan unik sebagai gambar Allah.

yang mereka miliki dan apa yang mereka pakai. ${ }^{14}$

Kedua, uang membeli "benda", sehingga dengan demikian kaum muda percaya bahwa memiliki banyak uang akan membawa kebahagiaan. Generasi ini adalah generasi yang paling makmur dalam sejarah dunia, generasi tanpa perang dengan teknologi yang semakin berkembang baik. Mueller melaporkan adanya kenaikan yang signifikan dari hasrat membeli kaum muda di Amerika Serikat beberapa tahun belakangan. ${ }^{15}$ Di tempat lain, Wilkins melaporkan sebuah survei, pada tahun 1970-an di Amerika, 70\% kaum muda mengambil gelar sarjana untuk membangun sebuah hidup yang bermakna, pada 1998 ketika survei ini dilakukan, hanya $40 \%$ yang berkata seperti itu, $75 \%$ anak muda mengambil gelar sarjana untuk membangun finansial yang baik. ${ }^{16}$ Jadi, kecenderungan anak muda untuk berbelanja, berbanding lurus dengan hasrat mencari uang yang semakin me-

12. Wilkins, Hidden Worldviews, 54.

13. Mueller, Youth Culture 101, 317-329.

14. Mueller, Youth Culture 101, 319. awal tulisan ini.

15. Mueller, Youth Culture 101, 320. Tidak te ralu berbedadengan anak muda di Indonesia yang penulis cantumkan di

16. Wilkins, Hidden Worldviews, 50.

\section{Youlfh}


ningkat. Kesimpulan tersebut cukup menunjukkan anak muda memiliki paradigma bahwa uang membawa kebahagiaan. Slogan "money is power" menjadi slogan yang membuat anak muda mencari uang, bahkan mereka merasa semakin memberi seseorang yang mereka cintai dengan barang yang mahal (contoh: cincin berlian, mobil, telepon genggam), semakin menunjukkan besar cinta mereka. Cinta pun diukur dengan uang! ${ }^{17}$

Ketiga, kepemilikan adalah sebuah jembatan untuk meraih penerimaan sosial. Kaum muda mempercayai bahwa ketika semakin mereka memiliki materi, mereka akan bisa bergabung ke dalam kelompok sosial tertentu dan menaikkan nilai diri mereka. Semakin bermerek (branded) apa yang mereka pakai semakin mereka nyaman dan bangga dengan diri mereka sendiri. Perkembangan sosial media seperti Facebook dan Instagram nampaknya turut memengaruhi perspektif anak muda yang seperti ini. ${ }^{18}$ Menurut Stage of Life survei, 61 dari responden mereka berkata bahwa berbelanja adalah alat untuk membangun ikatan di tengah keluarga atau pertemanan. ${ }^{19}$ Penelitian yang lain menyimpulkan bahwa pengeluaran utama remaja dan kaum muda adalah pakaian, baru setelah itu makanan dan aksesori. ${ }^{20}$ Bisa dilihat bahwa ada korelasi antara pengeluaran utama kaum muda berhubungan dengan kebutuhan untuk membangun jejaring sosial dan afirmasi sosial yang memang kebutuhan kaum muda.

Keempat, mereka tidak merasa salah dengan mementingkan diri sendiri dan memakai uang demi kebutuhan mereka. Maksudnya, kaum muda akan memakai uang, gaya hidup, dan apa yang mereka miliki berpusat pada diri sendiri dan tidak memikirkan orang lain. Meskipun masih ada, kepedulian kaum muda kepada orang-orang miskin dan terabaikan tidaklah terlalu menggembirakan. Di lapangan pelayanan, penulis melihat begitu biasa bagi anak remaja untuk menghabiskan puluhan hingga ratusan juta rupiah (bahkan miliar) hanya untuk menyelenggarakan pesta 17 tahun (sweet seventeen) yang heboh dan meriah.

Kelima, mereka tidak pernah merasa cukup. Kaum muda percaya bahwa standar kehidupan mereka adalah hidup lebih baik dan lebih berkecukupan dibandingkan orangtua mereka. Efek buruknya adalah banyak kaum muda yang mencari uang dan benda, dan akhirnya merasa tidak bertujuan dan tidak bermakna ketika mereka tidak mendapatkan apa yang mereka cari. Jika mereka berputus asa, mereka dekat sekali dengan depresi, drugs dan bunuh diri. ${ }^{21}$

Berdasarkan pemaparan di atas, dapat dilihat bahwa budaya postmodern memengaruhi makin merebaknya gaya hidup materalis kaum muda. ${ }^{22}$ Untuk menjawab problem tersebut, penulis

17. Wilkins, Hidden Worldviews, 48.

18. Rebbeca Lake, "23 Teenage Consumer Spending Statistics that will Shock You," https://www.creditdonkey.com/teenageconsumer-spending-stistic.html (diakses 13 November 2015).

19. Lake, "23 Teenage Consumer Spending Statistics that will Shock You."

20. Hayley Peterson, Everything You Need to Know about How Teens are Spending Money, What They Like, and Where They Shop, http://www.businessinsider.co.id/how-teens-are-spending-money-2014-2014-10/\#.VjjUyxmwrqA (diakses 9 November 2015).

21. Lake, "23 Teenage Consumer Spending Statistics that will Shock You."

22. Tidak berlebihan kalimat ini, "It is probably not an overstatement to say that consumerism (gaya hidup materialis dalam pembahasan penulis) is the most potent competitor to a Christian worldview in our culture." Wilkins, Hidden Worldviews, 50. 
menawarkan spiritualitas kesederhanaan (simplicity) sebagai jawaban bagi problem gaya hidup materialis kaum muda masa kini.

\section{Spiritualitas Kesederhanaan}

\section{Pemikiran Dasar Spiritualitas Kesederhanaan}

Richard Foster memberi definisi spiritualitas kesederhanaan (simplicity) sebagai berikut,"the Christian Discipline of simplicity is an inward reality that results in an outward life style." ${ }^{23}$ Spiritualitas kesederhanaan adalah realitas batin yang mewujud dalam gaya hidup lahiriah sehari-hari. Jika demikian, harus dipahami bahwa praktik kesederhanaan bukan sekedar tindakan menolak kekayaan saja lalu menjadi miskin, atau sekadar tindakan menghemat keuangan secara radikal. Namun praktik ini berasal dari keadaan batin yang diperbaharui oleh Allah dan kemudian mewujud pada praktik atau gaya hidup keseharian. Sebelum memaparkan konsep kesederhanaan dengan lebih lengkap, penulis menyadari, ada beberapa ketegangan yang perlu diperhatikan:

Pertama, praktik spiritualitas kesederhanaan adalah ketegangan antara anugerah dan disiplin. Artinya, kesederhanaan adalah anugerah karena hanya bisa dilakukan dengan kasih karunia dari Tuhan. Tetapi, kesederhanaan juga meminta ketaatan dan dis iplin secara sadar serta berkesinambungan dari pelaku. Anugerah dan kedisiplinan seperti sebuah pendulum, dua-duanya patut diperhatikan dalam praktik kesederhanaan. Kedua, kesederhanaan Kristen sama-sama mudah dan sekaligus sulit. Praktik ini mudah dalam artian jika sudah menjadi kebiasaan akan mudah untuk dihidupi, namun sekaligus sulit karena akan ada masa-masa bergumul dan upaya lebih dari pelaku praktik ini untuk menjadikannya kebiasaan. Ketiga, perlu keseimbangan yang terus menerus antara dimensi batin (inner) dan dimensi luar (outer) dari kesederhanaan. Keseimbangan in i supaya orang Kristen tidak terjatuh pada ekstrim satu dengan yang lain: hanya menekankan hal-hal lahiriah tetapi hati masih dikuasai kecemasan dan kekuatiran, atau merasa sudah aman atas pemeliharaan Tuhan tetapi tidak menunjukkan bukti lahiriah apapun. Keempat, paradoks dari kesederhanaan adalah penerimaan akan kebaikan benda-benda material sekaligus batasan dari benda-benda materi tersebut. Bendabenda materi sebagai bagian dari ciptaan adalah "baik" (Kejadian 1), namun "terbatas" karena kehidupan kita tidak ditentukan oleh benda materi saja. ${ }^{24}$ Selain ketegangan di atas, perlu diperhatikan bahwa praktik spiritualitas menuntut keseimbangan dengan praktik disiplin rohan i lainnya. Tanpa doa, firman Tuhan, serta keberadaan komunitas maka praktik ini akan menjadi asketisisme individualis semata. ${ }^{25}$

Sampai di sini, mungkin pembaca bertanya mengapa praktik spiritualitas ini layak dikerjakan sebagai gaya hidup

23. Richard J. Foster, Celebration of Discipline: The Path to Spiritual Growth 25th Anniversary (San Fransisco: Harper One, 1998), 79.

24. Richard Foster, Freedom of Simplicity: Finding Harmony in a Complex World (New York: Harper Collins, 2015), 9-11 25. Foster, Freedom of Simplicity: Finding Harmony in a Complex World. Bandingkan dengan penjelasan bahaya gaya spiritualitas askese oleh Gary Thomas dalam Sacred Pathways: Menemukan Jalan Spiritualitas Anda Menuju Allah (Yogyakar : Yayasan Gloria, 2011), 113-130.

\section{4}

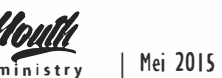


alternatif? Jawaban pada pertanyaan ini terdapat pada tujuan dari praktik spiritualitas kesederhanaan itu. Jan Johnson menulis,

Ketika kita mempraktikkan kesederhanaan, Roh Kudus mengarahkan kita untuk meninggalkan kesibukan dan bergegas keluar dari kehidupan kita untuk tetap berfokus pada Allah dan kerajaan-Nya. Kita menahan diri dari keterlibatan dalam banyak kegiatan dan dari memiliki bendabenda yang tidak berguna, serta tidak menjauh dari persatuan kita dengan Allah. Hasilnya adalah hati yang terfokus, sehingga kita menjadi lebih penuh pertimbangan dan memiliki tujuan dalam apa saja yang kita lakukan. ${ }^{26}$

Kesederhanaan membawa manusia kepada fokus dan kesatuan hidup batiniah, yaitu memusatkan pada Sang Ilahi. Kekurangpekaan manusia pada pemusatan batin kepada yang Ilahi itulah yang membuat manusia membutuhkan keamanan melalui keterikatan pada bendabenda. Dalam kehidupan anak muda, kurangnya gereja dalam memenuhi kebutuhan jiwa anak muda menyebabkan mereka mencari makna serta pemenuhan kebutuhan dalam gaya hidup materialis mereka. Jika kita meli hat tujuan dari praktik ini, bisa kita lihat betapa krusialnya praktik ini bagi kehidupan materialis modern.

\section{Teologi Spiritualitas Kesederhanaan}

Sekarang penulis akan memaparkan dasar teologis spiritualitas kesederhanaan. ${ }^{27}$ Foster menjelaskan bahwa Alkitab mempunyai bukti yang melimpah bagi spiritualitas kesederhanaan. Namun penulis hanya akan menjelaskan teologi kesederhanaan berdasarkan pengajaran Tuhan Yesus dalam Matius 6 yang menurut Foster "the most radiant passage on Christian simplicity in all bible." ${ }^{28}$ Spiritualitas kesederhanaan terlihat dari perintah Tuhan Yesus baik dalam bentuk negatif maupun positif "janganlah kamu mengumpulkan harta di bumi. . .," tetapi "kumpulkanlah bagimu harta di sorga." (6:19) Kata "harta" merujuk pada sesuatu yang berharga, sehingga maksudnya di sini bukan sekedar soal kekayaan dalam aspek uang, namun semua hal yang kita percayai di mana manusia terikat padanya, semua hal yang membuat manusia merasa kurang lengkap jika tidak memilikinya. ${ }^{29}$ Dalam perikop tersebut, Tuhan Yesus memberikan alasan mengapa manusia jangan sampai mencari harta di dunia:

Pertama, dunia adalah tempat yang sangat tidak pasti (6:19-20). Ketidakpastian itu dikarenakan tidak ada tempat untuk menyimpan harta di bumi. Metafora ngengat dan karat menunjukkan betapa keroposnya harta di bumi, sedangkan metafora pencuri menunjukkan kapan pun harta di bumi itu bisa diambil. Yesus menekankan bahwa seberapa amannya harta di dunia, ia akan gagal memberikan

26. Jan Johnson, Disiplin Rohani: Kesederhanan dan Puasa (Malang, Literatur SAAT, 2007), 12.

27. Lebih lengkap mengenai dasar teologis dalam sepanjang Alkitab. Foster, Freedom of Simplicity: Finding Harmony in a Complex World, 17-88.

28. Foster, Freedom of Simplicity: Finding Harmony in a Complex World, 40

29. Michael J. Wilkins, Matthew, The NIV Application Commentary (Grand Rapids: Zondervan, 2004), 293. 
keamanan kepada manusia.

Kedua, Yesus menegaskan bahwa apapun yang menjadi harta akan mengambil alih kehidupan kita. "Karena di mana hartamu berada, di situ juga hatimu berada." (Matius 6:20) Tuhan Yesus tegas berkata "di situ juga hatimu berada", menunjukkan unsur kepastian (bukan opsional) bahwa apa yang menjadi harta seseorang akan membuat pikiran seseorang berpusat pada sekitar harta itu. Perlu diingat di dalam Alkitab, hati adalah pusat dari kehidupan, ketika hati seseorang dikuasai oleh harta, maka saat itu pula kehidupan orang tersebut dikuasainya. ${ }^{30}$ Ketika Yesus berkata bahwa "tidak ada seorang yang dapat mengabdi kepada dua tuan," Tuhan Yesus menegaskan ketidakmungkinan mengabdi kepada dua Tuhan. Tuhan Yesus memberi ilustrasi dengan jelas "mata adalah pelita tubuhmu. Jika matamu, baik teranglah seluruh tubuhmu. Jika matamu jahat, gelaplah seluruh tubuhmu" (Mat 6:22-23a). Mata yang baik, atau terjemahan bahasa Inggrisnya "single eye" merujuk pada hidup yang memiliki tujuan yang satu atau terfokus, serta roh yang tidak egois dan berpusat pada diri sendiri. "Mata yang baik" dikontraskan dengan "mata yang jahat" yang berkonotasi dengan mata yang penuh iri hati atau keinginan. ${ }^{31}$ Hidup yang dikuasai oleh harta akan menghasilkan kehidupan yang egois dan tidak mementingkan kepentingkan sesama. Tuhan Yesus hidup dengan "single eye" atau hidup yang bertujuan atau berfokus pada kera- jaan Allah. Oleh karena itu, kehidupan spiritualitas kesederhanaan bukan sekadar soal penghematan uang atau pengeluaran, tetapi tentang hati yang berfokus kepada Tuhan Yesus dan Kerajaan Allah. Ketiga, alasan Yesusyang terakhir untuk tidak berfokus pada harta dunia adalah bahwa pemeliharaan itu sudah dilakukan oleh Allah. Melalui ilustrasi burung dan bunga bakung Tuhan Yesus hendak menyatakan bahwa pemeliharaan Allah begitu sempurna. Seseorang yang mempraktikkan spiritualitas kesederhanaan tidak akan kuatir mengenai hal-hal materi dalam hidupnya (6:34).

Terakhir, perikop ini mengajarkan kepada kita bahwa tidak menaruh harta di dunia akan membuat kita memfokuskan pada apa yang terpenting yaitu, mencari dahulu kerajaan Allah. "The central point for the discipline of simplicity is to seek the kingdom of God and the righteousness of his kingdom first and then everything necessary will come in its proper order." ${ }^{32}$ Mencari kerajaan Allah berarti menempatkan Allah sebagai tujuan, otoritas dan fokus dari hidup kita. ${ }^{33} \mathrm{De}$ ngan memfokuskan diri pada kerajaan Allah akan mengkreasi realitas batin yang dibaharui, orang tersebut akan dibebaskan dari rasa mencari keamanan yang didapat dari materi, prestasi, posisi atau apapun yang ada di dunia ini. Pada bagian berikut penulis memaparkan dampak dari teologi kesederhanaan kepada realitas batin dan luar kehidupan manusia.

30. R. T. France, The Gospel of Matthew, The New International Commentary on the New Testament (Grand Rapids: Eerdmans, 2007), 260

31. Foster, Freedom of Simplicity: Finding Harmony in a Complex World, 40-41.

32. Foster, Celebration of Discipline, 86.

33. Leon Morris, The Gospel According to Matthew (Grand Rapids; Inter-Varsity Press, 1992), 161.

\section{Youlfll}


Realitas Batin dan Realitas Luar Spiritualitas Kesederhanaan

Pertama, penulis akan memaparkan mengenai realitas batin. Penulis telah menjelaskan dasar spiritualitas kesederhanaan adalah fokus pada kerajaan Allah. Ada tiga ukuran realitas batin dari spiritualitas kesederhanaan yang menunjukkan fokus tersebut mulai menguasai batin pelaku spiritualitas ini.

(i) Seseorang yang mempraktikkan spiritualitas kesederhanaan akan menerima kebenaran bahwa yang dimilikinya adalah karunia dari Allah. Manusia bekerja, berusaha, berupaya dalam hidup setiap hari, seseorang yang realitas batinnya diperbaharui akan melihat bahwa apa yang ia miliki, tiada terkecuali semuanya adalah pemberian Allah.

(ii) Seseorang yang mempraktikkan spiritualitas kesederhanaan akan mengerti bahwa karya Allah saja yang memelihara apa yang manusia miliki. Tuhan dapat membuka dan menutup pintu, kapan pun dan dengan cara bagaimanapun. Jika ukuran ini telah dimiliki, seseorang tidak akan mudah cemas mengenai pekerjaan, keuangan, atau apa yang ia miliki.

(iii) Seseorang yang mempraktikkan spiritualitas kesederhanaan akan menampilkan kebaikan pada orang lain. Jika kebaikan dan kemurahan hati tidak nampak pada komunitas dan sesama, maka orang tersebut belum mencapai titik fokus spiritualitas kesederhanaan.

Kedua, penulis menguraikan mengenai realitas luar yang terwujud dalam gaya hidup keseharian.

(i) Pelaku spiritualitas kesederhanaan akan membeli sesuatu untuk kebutuhan daripada sekedar sebuah "status." Menolak perspektif materialis, seorang yang memiliki hati terpusat kepada Allah akan selalu bertanya: "apakah saya membutuhkan hal itu sebagai pendukung tugas perutusan saya di tengah dunia?" Dalam praktiknya, pelaku spiritualitas ini pasti akan membuat pengaturan pengeluaran bulanan dan menaatinya secara disiplin. Jadi bukan lagi slogan aku berarti ketika aku memiliki yang menjadi prinsip, namun aku memiliki apa yang Allah rindu aku miliki.

(ii) Pelaku spiritualitas kesederhanaan akan menolak segala sesuatu yang memproduksi "kecanduan." Internet, video, film, games, liburan yang berlebihan, akan membuat kita kecanduan. Kecanduan merujuk pada segala sesuatu yang membuat kita menghabiskan sumber daya kita pada hal tersebut, bahkan kehilangan hal tersebut akan membuat emosi kita meledak. Spiritualitas kesederhanaan menolong manusia untuk tidak terikat pada benda-benda material.

(iii) Pelaku spiritualitas kesederhanaan akan membangun sebuah kebiasaan untuk melepaskan apa yang kita punya dengan memberikannya pada orang lain. Seorang yang mempraktikkan spiritualitas kesederhanaan akan memahami bahwa apa yang dimilikinya adalah pemberian untuk dibagikan kepada orang lain. Ingat ukuran realitas batin yang ketiga!

(iv) Pelaku spiritualitas kesederhanaan akan belajar untuk menikmati sesuatu tanpa memiliki. Pelaku spiritualitas kesederhanaan akan tetap merasa cukup tanpa memiliki apa yang mereka inginkan, masih ada buku yang bisa dipinjam, film 
yang bisa ditonton di TV, olahraga yang dilakukan tanpa membayar, dan lain sebagainya.

(v) Pelaku spiritualitas kesederhanaan akan melihat dengan skeptis kepada motto: "ambil sekarang, bayar nanti" alias berhutang! Kebiasaan berhutang adalah kebiasaan buruk yang sebenarnya berakar dari gaya hidup materialis, bahwa kita harus memiliki segala sesuatu bagaimanapun caranya. Penulis merasa gereja perlu memperlengkapi kaum muda dan jemaat umumnya, untuk tidak terjebak pada jerat kartu kredit.

(vi) Pelaku spiritualitas akan menekankan latihan jiwa "istirahat" dan tidak membiarkan dirinya dikuasai kesibukan. Karena segala sesuatu dikerjakan oleh Allah, susah-payah kita tidak menambahinya, pelaku spiritualitas ini akan mengutamakan kesehatan jasmani, beristirahat dengan cukup dan tidak membiarkan dirinya digerus oleh kesibukan kerja. Gereja perlu memperlengkapi anak muda untuk bisa memiliki "tidur" sebagai latihan jiwa, serta menyepi (solitude) dan refleksi sebagai disiplin rohani yang membawa mereka untuk memakna hidup batiniah mereka. Sesungguhnya, praktik lahiriah atau dimensi luar dari spiritualitas kesederhanaan masih bisa dikembangkan melampaui poin-poin di atas, namun penulis merasa poin-poin tersebut yang paling dapat diaplikasikan bagi kehidupan anak muda.

\section{Epilog: Refleksi bagi Youth Pastor}

Penulis telah menguraikan tentang gaya hidup materialis dan menawar- kan spiritualitas kesederhanaan (simplicity) sebagai jawaban terhadap problem gaya hidup materialis yang ada. Jika kaum muda mampu mempraktikkan spiritualitas kesederhanaan, maka mereka tidak akan terjatuh pada kekosongan jiwa, kenikmatan sesaat serta keterikatan semu akibat mengikuti pola hidup materialis, namun mampu mengarahkan diri pada fokus kerajaan Allah.

Lalu apa yang menjadi refleksi bagi para pengerja kaum muda? Pengerja kaum muda perlu menjadi teladan dalam mempraktikkan disiplin kesederhanaan sebagai rule of life ${ }^{34}$ dan mengajarkannya sebagai bagian dari kurikulum gereja. Penulis menjumpai cukup banyak rekan pelayan kaum muda yang terjatuh dalam jebakan gaya hidup materialis dengan alasan yang terkadang "rohani" yaitu untuk mengikuti perkembangan zaman dan mudah memengaruhi kaum muda. Alasan ini menyebabkan banyak pelayan kaum muda, penginjil, hamba Tuhan yang merasa minder jika handphone mereka bukanlah produk keluaran terbaru, baju mereka tidak branded, atau bahkan penampilan di mimbar tidak entertaining. Itu semua penting namun bukan yang terutama. Penulis percaya bahwa anak muda mencari sesuatu yang melampaui hal-hal tersebut, dan lebih merindukan seorang pelayan kaum muda yang mencintai Tuhan Yesus serta menghadirkan Tuhan dalam keseharian mereka. Setelah menjadi teladan, secara sadar dan terencana gereja perlu memasukkan disiplin rohani kesederhanaan sebagai bagian dari kurikulum pembinaan gereja. Camp Live In di desa, mission trip ke orang-orang terabaikan, serta aksi sosial akan me-

34. Mike King, Presence-Centered Youth Ministry: Guiding Studen into Spiritual Formation (IVP Press: Downers Grove, 2006) 156-157; bdk. Mueller, Youth Culture 101, 328-329.

\section{Toulf}


nolong anak muda untuk mengembangkan gaya hidup ini. Dipadu dengan praktik disiplin rohani semacam solitude, doa-doa kontemplatif akan membuat realitas batin ini terbangun secara perlahan. ${ }^{35}$

Akhir kata, pelayanan kaum muda adalah sebuah maraton yang panjang dan tidak akan pernah usai, sehingga pengerja kaum muda semestinya belajar menjadi orang-orang yang setia dan berdaya tahan tinggi untuk bertahan dalam maraton yang melelahkan ini. Bersediakah kita? In His Grace, For His Glory!

\section{Daftar Pustaka}

Admin, "Tren Gaya Hidup Anak Muda." http://www. marketing.co. id/tren-gayahidup-anak-muda-asia/ (diakses 1 November 2015).

Dunn, Richard R. Membentuk Kerohanian Anak Muda di Zaman Postmodern. Surabaya, Literatur Perkantas Jatim, 2012.

Foster, Richard. Celebration of Discipline: The Path to Spiritual Growth 25th Anniversary. San Fransisco: Harper One, 1998.

. Freedom of Simplicity: Finding Harmony in a Complex World. New York: Harper Collins, 2015.

France, R. T. The Gospel of Matthew. The New International Commentary on the New Testament. Grand Rapids: Eerdmans, 2007.

Guharoy, Debnath. "Analysis: How Powerful is the Young Indonesian Consumer?" http://m. thejakartapost. com/news/2010/10/26/how-powerful-youngindonesian-consumer. html (diakses 3 November 2015).

35. Penulis menyarankan pembaca untuk membaca Mark Yaconelly, Downtime: Helping Teenagers Pray (Zondervan: Youth Specialties, 2006). 
Johnson, Jan. Disiplin Rohani: Kesederhanan dan Puasa. Malang, Literatur SAAT, 2007. Kamus Besar Bahasa Indonesia. http://kbbi. web. id/materialis (diakses 13 November 2015).

King, Mike. Presence-Centered Youth Ministry: Guiding Students into Spiritual Formation. IVP Press: Downers Grove, 2006.

Kinnaman, David dan Gabe Lyons. UnChristian: What a New Generation Really Thinks about Christianity and Why It Matters. Grand Rapids: Baker Books, 2007.

Kinnaman, David. You Lost Me: Mengapa Orang Kristen Muda Meninggalkan Gereja dan Memikirkan Ulang tentang Iman Mereka. Bandung: VisiPress, 2011.

Lake, Rebbeca. "23 Teenage Consumer Spending Statistics that will Shock You," https://www. creditdonkey. com/teenage-consumer-spending-statistic. html (diakses 13 November 2015).

Morris, Leon. The Gospel According to Matthew. Grand Rapids; Inter-Varsity Press, 1992.

Mueller, Walt. Youth Culture 101. Grand Rapids: Youth Specialties, 2007.

Noviyanti, Sri. "Anak-Anak Muda Makin Gila Belanja." http://m.kompas.com/female/read/2015/10/26/141514920/Anakanak.Muda.Makin.Gila (diakses 30 Oktober 2015).

Oxford Dictionaries. http://www. oxforddictionaries. com/definition/english/ materialism (diakses 3 November 2015

Peterson, Hayley. Everything You Need to Know about How Teens are Spending Money, What They Like, and Where They Shop http://www. businessinsider. co. id/how-teens-are-spending-money-2014-2014-10/\#. VjjUyxmwrqA (diakses 9 November 2015).

T. n, "Fakta Menarik tentang Anak Muda di Tanah Air." http://riseup. id/ini-faktamenarik-tentang-anak-muda-tanah-air/ (diakses 1 November 2015).

Thomas, Gary. Sacred Pathways: Menemukan Jalan Spiritualitas Anda Menuju Allah. Yogyakarta: Yayasan Gloria, 2011.

Wilkins Michael J. Matthew. The NIV Application Commentary. Grand Rapids: Zondervan, 2004. 
Wilkins, Steve dan Mark L. Sanford. Hidden Worldviews: Eight Cultural Stories that Shapes Our Lives. Downers Grove: IVP Press, 2009.

Yaconelly, Mark. Downtime: Helping Teenagers Pray. Zondervan: Youth Specialties, 2006. 